\title{
Effects of Cross Jet on Turbulent Main Stream Flow in A Non-Circular Elbow - A Numerical Approach
}

\author{
RABIN DEBNATH ${ }^{1}$, SOMNATH BHATTACHARJEE ${ }^{2}$, ARINDAM MANDAL $^{3}$, \\ SNEHAMOY MAJUMDER ${ }^{4}$ AND DEBASHIS ROY ${ }^{4}$ \\ ${ }^{1}$ Principal, Govt. ITI for P.C.B. \& G., Kolkata, T.E.T. \& S.D. Department, \\ Govt. of West Bengal, Kolkata Karigori Bhavan, Pin-700 013, INDIA \\ ${ }^{2}$ Senior Technical staff-member, C.S.E. Dept., Jadavpur University, Kolkata \\ Jadavpur, Pin-700 032, INDIA \\ ${ }^{3}$ Mechanical Engineering Dept., Heritage Institute of Technology, Kolkata \\ Anandapur, Pin-700 107, INDIA \\ arindam.mmeju@gmail.com http://www.heritageit.edu/ \\ ${ }^{4}$ Mechanical Engineering Dept., Jadavpur University, Kolkata \\ Jadavpur, Pin-700 032, INDIA
}

\begin{abstract}
The performance of fluid transportation model through non-circular elbow ducts with wall mass injection in predicting the velocity and pressure fields is important in Industrial applications. The present work pertains to the two-dimensional numerical analysis of the developing turbulent fluid flow with uniform mass injection through the top wall of a rectangular elbow. A numerical experimentation using control volume formulation considering standard $k-\varepsilon$ turbulence model has been conducted to study different parameters like the velocity distributions, size and shape of the recirculation bubble as well as the friction factor etc. The size and strength of the recirculation bubbles generated in the bend regions are affected by the continuous entry of mass injected through the wall of the elbow. The results show that the velocity field, reattachment points, friction factor etc. are influenced by the side mass injection. The recirculation bubble has been observed to diminish in size by the injection of mass with corresponding changes in the velocity and the friction factors.
\end{abstract}

Key Words: Turbulent Flow, Recirculation, Wall injection flow, Non-circular elbow.

Received: November 11, 2019. Revised: May 14, 2020. Accepted: May 25, 2020. Published: June 10, 2020.

\section{Introduction}

The developing turbulent flow in non-circular ducts with one-walled fluid injection or suction of additional mass into the main flow has been widely encountered in engineering applications, including the design and analysis of nuclear reactors, combustion chambers, food-drying processes, fuel cell stacks, purification processes by reverse osmosis and also bend ducts or pipes used for industrial flow applications. Clear understanding of fluid flow is essential for developing reliable design tools for a wide range of energy saving as well as conversion devices such as compact heat exchangers, electronic circuitry cooling systems, cooling channels in gas turbine blades, ventilation and air-conditioning systems and heat ducts used in thermal power and chemical process plants. The main flow in such ducts is influenced by the secondary motions in the plane perpendicular to the stream wise direction, commonly referred as the secondary flow, causing distortion of the axial flow. In the bend regions effect of secondary flow and consequent vortices are predominant, thus significantly impacting the main axial fluid flow performance of the duct devices. Several studies on turbulent fluid flow in ducts or pipes etc. with wall injection have been extensively conducted during the past decades and they are available in the literature. In their study, Dutta and Nandi [1] expressed their views that secondary flow superimposed on primary axial flow is formed in a pipe bend during fluid flow due to centrifugal force. Secondary flow is dependent on curvature ratio, Reynolds number and flow condition. Wang, Ren, Sun, Yang and $\mathrm{Tu}$ [2] described in their study the development of secondary flow and flow separation in the case of $90^{\circ}$ elbow. They had also remarked that the flow at the central part and along the circumference wall is influenced by the centrifugal action and the pressure difference respectively. $\mathrm{Wu}$, Liu, Luo, Chen and Dai [3] studied the flow field 
characteristics of the $90^{\circ}$ rectangular elbow in pushpull ventilation device. Debnath, Bhattacharjee, Roy and Majumder [4] analysed experimentally the turbulent air flow in a two-dimensional rectangular elbow at high Reynolds numbers. They investigated the velocity profiles, flow separation, re-circulation and friction drag etc. in detail. In their study, the effects of Reynolds numbers on the variable discharge of the blower coupled with inlet of the elbow and the possible existence of the recirculation zones generated in the flow region had also been investigated. MOSSAD, YANG and SCHWARZ [5] carried out the numerical study on sharp rightangled elbow where energy loss is more than curved elbow because of the formation of a separation zone. Hossain and Hossain [6] analyzed the velocity distribution and formation of flow pattern throughout the bent channel and compared the computational results with $k-\varepsilon$ and Reynolds Stress Model. In another study, Hossain, Hossain, Pramanik and Ahmed [7] investigated the deviation of turbulent kinetic energy, turbulent dissipation rate, eddy viscosity and turbulent intensity with the rise of Reynolds number through the bent region of curved pipe using $k-\varepsilon$ and $\mathrm{k}-\omega$ turbulent model. Rathore, Mondloe and Upadhyay [8] analyzed the flow characteristics of $90^{\circ}$ bent pipe computationally using finite volume method and compared the results so obtained with the straight pipe having the equal length using ANSYS Fluent. Baydar and Ozmen [9] had carried out an experimental as well as numerical study to investigate flow field of a confined jet issuing from the lower surface and impinging normally on the upper surface. The mean velocity, turbulence intensity and pressure distributions in the impingement region were obtained for Reynolds numbers ranging from 30,000 to 50,000 and a nozzle-to-plate spacing range of $0.2 \mathrm{~m}-6 \mathrm{~m}$. Devahastin and Mujumdar [10] numerically studied the flow patterns and mixing characteristics of 2-D confined laminar impinging slot streams, using control-volume-based computational fluid dynamic (CFD) software (PHOENICS Version 2.2.2). The numerical predictions of turbulent plane jets discharged normal to a weak or moderate cross stream flow were presented by Kalita, Dewan and Dass [11]. The predictions were presented to illustrate the flow pattern involved and to assess the performance of the standard $k-\varepsilon$ model by comparison with the available experimental observations of Ramaprian and Haniu [12] and Haniu and Ramaprian [13] for three different jet to cross stream velocity ratios six, nine, and ten respectively. Devahastin and Mujumdar [14] performed a parametric study of the flow and mixing characteristics of 2-D confined turbulent opposing-slot jets, using a new composite turbulence model that they developed by incorporating the Yap correction and a formula for the turbulent (eddy) viscosity into a low-Re $k-\varepsilon$ model. The structure of the flow generated by the interaction of suction into a circular inlet and a cross-flow was studied by Hold, Calay and O'Brien [15] using flow visualization and experimental measurements with hot-wire anemometer and yaw probes. This study investigated the flow field close to the inlet hole generated by the interaction between the cross-stream flow and the suction flow into the inlet. In the year 1961, the authors Ricou and Spalding [16] carried out an experimental investigation for turbulent axi-symmetric jets. Their experimental works provided the measurements of free jet entrainment parameter. After 5 years, Olson and Eckert, [17] conducted a bench mark experimental study on the fully developed turbulent flow of air at $\operatorname{Re}=28,000$ to 82,000 entered uniformly through a porous circular tube wall. They observed a reduction of friction factor due to the side injection in a turbulent main flow. Exley and Brighton [18] were among the leading researchers to estimate the size of the recirculation zone with the central jet flow. The effect of variation in the velocity ratio between the inner and outer jets on the separation and reattachment of the flow was examined theoretically and experimentally. The standard $k-\varepsilon$ model was employed by Elghobashi, Pun and Spalding [19] to predict the separation and reattachment zones in coaxial jet flows successfully. Experimental and analytical studies of the jet in a cross-flow had been conducted by a number of investigators. It was reported by Andreopoulos and Rodi [20] on measurement in flow generated by a jet issuing from the circular outlet in a wall into a cross-stream along this wall. The outcome were the estimation of threedimensional mean flow, turbulence fields and the physical explanation of various phenomena associated as well as their dependence on the velocity ratio. Pietrzyk, Bogard and Crawford [21] presented the results of a detailed hydrodynamic study of row of inclined jets issuing into a crossflow. Khodadadi and Vlachost [22] performed both the numerical and experimental study of confined coaxial turbulent jets for the turbulent mixing of a primary jet and its surrounding fluid in a pipe with inlet conditions. Detailed profiles of the axial mean and R.M.S. velocities were measured with a laser 
Doppler anemometer and they observed strong flow separation near the wall of pipe. Yang, Tsai and Tsai [23] experimentally investigated the effect of uniform mass bleeding in the direction normal to the bulk turbulent flow over a back step. Roy and Bertrand [24] performed a theoretical and experimental study on 2-D laminar flow mixing in a $\mathrm{Y}$-junction similar to the opposing jet flow. The effects of the angle between the two branches of a Y junction and the air flow rate on the flow patterns were examined numerically and analytically. Their experiments showed that the flow in the exit became unstable at a critical Reynolds number of $\operatorname{Re}>500$ when the axis of the two inlet jets was in the directly opposed direction. A numerical investigation of the mixing characteristics of opposing heated line jets with a horizontal cross-flow in rectangular channel was done by Chang and Chen [25] using a turbulence $k-\varepsilon$ model. They emphasized for the effects of momentum flux ratio and incident angle on the mixing behavior of lateral jets with the crossflow. Fric and Roshko [26] and Kelso, Lim and Perry [27] observed that the interaction of the jet flow with the cross-stream produced large scale coherent structures or vortices in the flow field, which control the mixing processes. These structures along with the side wall effect make the flow field complex and three-dimensional. However the three-dimensional effects may not be significant in certain regions of the flow field. Dianat, Fairweather, and Jones [28] had made predictions of axi-symmetric and two-dimensional impinging turbulent jet with a standard $k-\varepsilon$ turbulence model. In earlier, the standard $k-\varepsilon$ model of Launder and Spalding [29] has been used extensively to simulate the turbulent round jets in a cross flow. Patankar, Basu and Alpay [30]; Catalano, Chang and Mathis [31]; Hwang and Chiang [32]; He, Guo, and Hsu [33] and many others have predicted round turbulent jets in a weak and moderate cross flow (R, jet to cross stream velocity ratio $\geq 2$ ) using the standard $k-\varepsilon$ turbulence model. Ajersch, Zhou, Ketler, Salcidean, and Gartshore [34] investigated the interaction of multiple jets in cross flow both experimentally and numerically. Liou, Liao, Chen, and Lin [35] studied the turbulent flow fields resulting from an oblique jet injecting from a rectangular side-inlet duct into a rectangular main duct with an aspect ratio 3.75 without a forced cross-flow in terms of laserDoppler velocimetry measurements. The main focuses were the effects of the side jet angle $(\theta)$ and side-jet flow rate (Qs) on the mass entrainment upstream of side-jet port and the flow field in the rectangular duct. A numerical study of Ali, Fujiwara, and Leblanc [36] on mixing and combustion of hydrogen transversely injected into a main airstream was carried out by solving twodimensional full Navier-Stokes equations, with an aim to increase the mixing and combustion efficiencies of the injected fuel. Hahn, Je and Choi [37] employed the Direct Numerical Simulation (DNS) technique for analyzing turbulent channel flow with permeable walls. They predicted a reduction of viscous sub layer thickness due to side mass injection flow. Nirmolo [38] studied the multiple jets radially injected inwardly from a cylindrical chamber wall and outwardly from a chamber centerline into a cross-flow by experimental method and numerically using FLUENT-CFD code. The chamber diameter was varied from $0.3 \mathrm{~m}$ to $3.0 \mathrm{~m}$ and the number of nozzles from 4 to 32.The authors Beheshti, Ghorbanian, Farhanieh, Teixeira and Ivey [39] evaluated the stability margin with various mass flow rates and angles of injection in an axial compressor. Cassina, Beheshti, Kammerer and Abhari [40] studied on the aspect ratio of injector and the injection angle in an axial compressor stage equipped with the discrete tip injections. Disimile and Toy [41] experimentally investigated the confined vortex dominated jet flow in cross flow and concluded that the flow in the downstream became very complicated than the free jet in cross flow, indicating flow instability. They estimated the changes of the vertical structures and correlated it with the downstream distance. In the same year, the numerical investigation of Ko [42] was to find out the effects of side mass injection at different angles on the mixing phenomena. He concluded that the secondary flow becomes influential when the side injection angle increases and mixing gets enhanced. The effects of the streamline curvature and finite edge velocity on the flow field of a turbulent plane jet in cross-flow were studied by Pathak, Dewan and Dass [43] numerically by incorporating the curvature effect in the $k-\varepsilon$ turbulence model. Majumder and Sanyal [44] had shown the reduction of the predicted friction factor, recirculation zone, turbulent shear stress and turbulent energy flux with increase in the side injection velocity in turbulent pipe flow. Saha, Majumder and Sanyal [45] carried out a numerical investigation employing modified $k-\varepsilon$ model for the turbulent flow through an axi-symmetric circular duct with side mass injection at various injection angles to resolve the re-circulation flow regions with increase of injection angle. The numerical study of Kumar and Das [46] of the turbulent dual 
jet comprising of a plane wall jet and a plane offset jet had been carried out using the standard high Reynolds number two-equation $k-\varepsilon$ turbulence model. Majumder, Saha and Das [47] conducted a numerical investigation to study the effects of twin turbulent side mass injection with cross flow through a circular duct using modified $k-\varepsilon$ model considering $1 / 7$ th turbulent velocity profile at inlet of a circular duct. A parametric study of DaeWoong Kim, Jin-Hyuk Kim and Kwang-Yong Kim [48] on the aerodynamic performance of a transonic axial compressor combined with a groove and tip injection was performed using three-dimensional RANS equations. Recently, Ma and Lai [49] made a good comparative study of five most widely used two-equation turbulence models in predicting the developing flows in two $90^{\circ}$ curved rectangular ducts. These include the standard $k-\varepsilon$ model, the shear stress transport $\mathrm{k}-\omega$ model, and three lowReynolds number $k-\varepsilon$ models by Jones and Launder, Launder and Sharma, and Nagano and Hishida respectively. The paper has provided a detailed comparative verification for applying the five most widely used two-equation turbulence models to predicting curved rectangular duct flows, which are a kind of proto-type flows in fluid engineering. Their numerical results indicate that the computation efficiency of the standard $k-\varepsilon$ model is the highest among the five turbulence models for both the fully three-dimensional and the nominally two dimensional $90^{\circ}$ - curved duct flows. Much research has been carried out relating to the interaction of confined mainstream turbulent flow with cross jet flow. On the other hand, information for the case where the turbulent fluid is injected into the turbulent mainstream turbulent flow in doubleelbow duct seems to be limited. The published literatures report only a very few studies on noncircular bend ducts incorporating mixed mode analysis of the turbulent fluid velocity field due to the effect of side mass injection through the duct wall. The flow characteristic in any non-circular duct with wall injection is more complex than those for solid walls. . Study of such a complex flow in a bend non-circular duct is very important for having useful information about the turbulent flow field from which the complex re-circulatory flow is generated in the bend regions. At present little information is available on such flows apart from that detailed by the authors in the present study.

The standard $\mathrm{k}-\varepsilon$ turbulence model has been widely used in modeling mixing the flow field in presence of side mass injections for combustion chamber and other many industrial fluid flow and heat transfer applications because of its robust and reasonable accuracy in predicting complex flows; good agreement between predicted and experimental data was also observed in different engineering problems. Therefore, the standard $k-\varepsilon$ model in CFD code FLUENT 6.3 has been selected to model the problem of cross jet on turbulent main stream flow in a circular elbow in the present study.

\section{Physical Model and Solution Method}

The study of strength and stabilization of the recirculation bubble due to wall injection flow is important to research scholars, because of its relevance to reduction of momentum energy loss. The experimentation is much expensive; the numerical method is therefore chosen here to obtain the results. In the present work, the inward uniform line jets are discharged at an angle 900 through the upper wall into a mainstream cross flow in an elbow. A detail physical model of a fixed twodimensional axi-symmetric elbow duct with its injection grooves used for the present numerical experimentation is illustrated in Figure1.The mainstream flow is incompressible, steady and turbulent in an elbow with aspect ratio for its rectangular cross section depth to length is $1: 11$. The working fluid is air allowed to enter with its uniform velocity profile at a constant value, $\mathrm{u}_{\mathrm{in}}=5 \mathrm{~m} / \mathrm{s}$ corresponding to $\mathrm{Re}_{\mathrm{in}}=40900$. The inlet and wall temperatures remain constant as $300 \mathrm{~K}$ throughout the experiment. The top wall injection slot width of $\mathrm{w}_{\text {inj }}=0.03 \mathrm{~m}$ has been chosen for the work. The density and dynamic viscosity of the working fluid air are taken as $\rho_{\text {air }}=1.133 \mathrm{~kg} / \mathrm{m}^{3}$ and $\mu_{\text {air }}=1.87 \times 10^{-5} \mathrm{~kg} / \mathrm{ms}$ respectively.

The control volume formulation of Patankar [50] with Power law scheme is adapted for solution of re-circulating flows generated in the mainstream turbulent flow field in an elbow. The numerical method provides the 2-D results of velocity field, recirculation bubble size and skin friction along the walls of the elbow.

The present work is concerned with the numerical study of velocity distributions downstream the injection flow held through the top wall in an elbow duct. The 2-D time-averaged governing continuity and momentum equations for an incompressible, Newtonian fluid and steady turbulent flow along with standard $k-\varepsilon$ turbulence model equations in Cartesian co-ordinate (x, y) system have been 
computationally solved based on some boundary conditions. The standard wall function of Launder and Spalding [29] has also been adopted for the solution of the standard $k-\varepsilon$ equations for the turbulent flow near the boundary wall region.

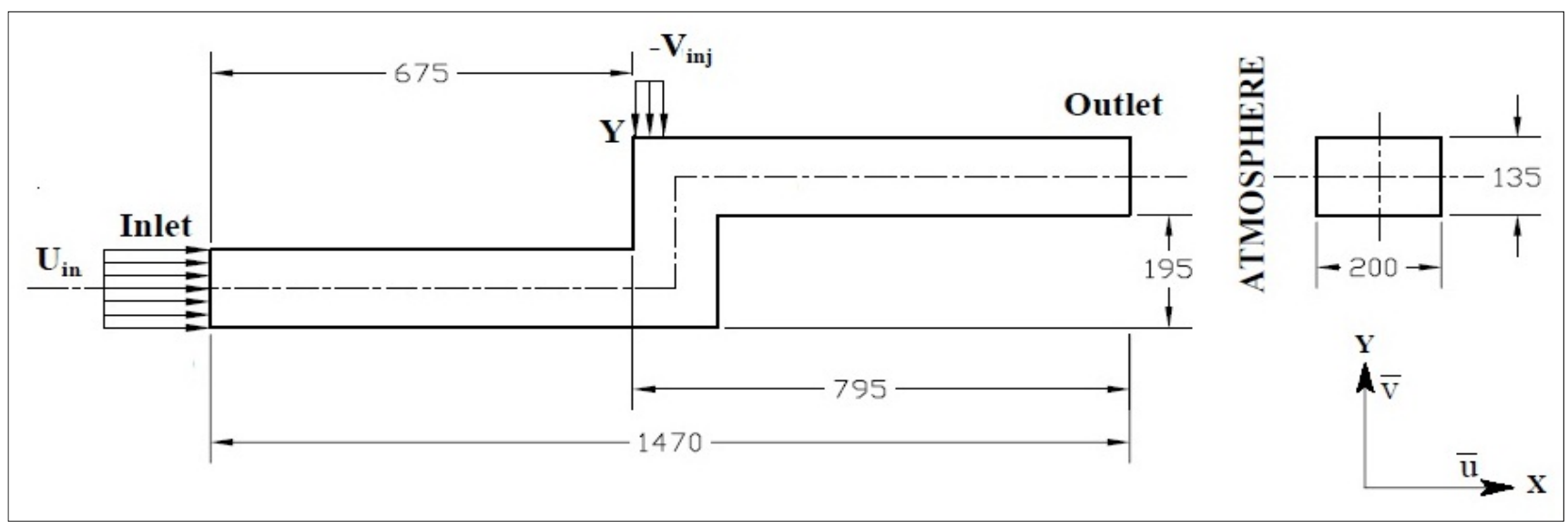

Figure 1. Schematic 2-D views of physical model and coordinate system (All dimensions are in mm)

\subsection{Numerical Procedure}

A numerical calculation to predict the developing mainstream turbulent flow with an inward injection flow through the upper wall injection slot inside an elbow of rectangular cross-section has been performed. A two-dimensional (2-D) rectangular coordinate $(\mathrm{x}, \mathrm{y})$ system has been considered for the analysis, and the mean flow components in $\mathrm{x}, \mathrm{y}$ directions have been resolved based on some boundary conditions. The effect of the one-walled inward radial turbulent injection flow on the mainstream turbulent fluid flow through the elbow has also been analysed. The current method also provides the corresponding changing values in the velocity and skin friction factors along the walls of the elbow. The 2-D time-averaged turbulent NavierStokes and standard $k-\varepsilon$ turbulence model equations with standard wall function empirical laws are solved numerically along with the continuity equation to simulate the turbulent flow field in an elbow. To simplify the numerical simulation by using a 2-D mathematical model with Control volume scheme, the flow properties are assumed constant throughout the elbow. The control volume formulation of Patankar [50] with Powerlaw scheme is taken into account as a basis for solution of re-circulating flows generated in the mainstream turbulent flow field in an elbow. The standard wall function of Launder and Spalding [29] has also been adopted for the solution of the standard $k-\varepsilon$ equations for the turbulent flow near the boundary wall region. The CFD code Fluent@ v.6.3 has been employed as the platform in the simulation effort for the numerical work. The results of the computational simulation with an improved accuracy for the given physical model are exhibited and plotted accordingly for discussion and making conclusions finally.

\subsection{Mathematical Modeling}

The mathematical modeling, numerical techniques and grid independence study employed for Computational Fluid Dynamics (CFD) analysis of systems are considered in order to obtain numerical solution of the governing equations of the turbulent fluid flow. The mathematical equations governing the turbulent incompressible Newtonian fluid flow and convection heat transfer are formulated based on three physical principals: (1) the law of conservation of mass, (2) the law of conservation of momentum and (3) the law of conservation of energy. In the mathematical description of fluid flow it is necessary to assume that quantities such as velocity, pressure and temperature vary continuously from one point to another. This is the assumption of continuum. In mathematical representation of the physical principles implemented for incompressible turbulent fluid along with the concept of continuum the governing equations are formulated in the form of partial differential equations. The conservation equation for mass is referred as continuity equation and the conservation equations for momentum are called momentum (Navier-Stokes) equations. The twodimensional time-averaged governing continuity and momentum equations for an incompressible, Newtonian fluid and steady turbulent flow along 
with standard $k-\varepsilon$ turbulence model equations in Cartesian co-ordinate (x, y) are as follows:

\subsubsection{Conservation of Mass}

Continuity equation: $\frac{\partial \bar{u}}{\partial x}+\frac{\partial \bar{v}}{\partial y}=0$

\subsubsection{Conservation of Momentum}

X-Component equation:

$\frac{\partial(\bar{u} \bar{u})}{\partial x}+\frac{\partial(\bar{v} \bar{u})}{\partial y}=-\frac{1}{\rho} \frac{\partial \bar{p}}{\partial x}+2 \frac{\partial}{\partial x}\left(\frac{1}{\rho} \mu_{e f f} \frac{\partial \bar{u}}{\partial x}\right)$

$+\frac{\partial}{\partial y}\left\{\frac{1}{\rho} \mu_{e f f}\left(\frac{\partial \bar{u}}{\partial y}+\frac{\partial \bar{v}}{\partial x}\right)\right\}$

Y-Component equation:

$\frac{\partial(\bar{u} \bar{v})}{\partial x}+\frac{\partial(\bar{v} \bar{v})}{\partial y}=-\frac{1}{\rho} \frac{\partial \bar{p}}{\partial y}+2 \frac{\partial}{\partial y}\left(\frac{1}{\rho} \mu_{\text {eff }} \frac{\partial \bar{v}}{\partial y}\right)$

$+\frac{\partial}{\partial x}\left\{\frac{1}{\rho} \mu_{e f f}\left(\frac{\partial \bar{v}}{\partial x}+\frac{\partial \bar{u}}{\partial y}\right)\right\}$

Where $\bar{u}, \bar{v}, \bar{p}$ are the time-averaged mean velocity components along $\mathrm{x}$ and $\mathrm{y}$ directions and the mean pressure of the turbulent fluid respectively.

According to Prandtl-Kolmogorov relation the derived formula for eddy viscosity is given by $\mu_{\mathrm{t}}=\rho \mathrm{C}_{\mu}\left(\frac{\kappa^{2}}{\varepsilon}\right), v_{\mathrm{t}}=\mathrm{C}_{\mu}\left(\frac{\kappa^{2}}{\varepsilon}\right) ; \quad v_{t}, C_{\mu} \quad$ are turbulent kinematic viscosity and empirical turbulence constant, while, $k$ and $\varepsilon$ stand for turbulent kinetic energy and its dissipation rate respectively.

\subsubsection{Turbulence Modeling}

Standard $k-\varepsilon$ equations (SKE) for turbulent fluid flow:

The model transport equations for scalars $(k, \varepsilon)$ is governed by the principal of Advection $=$ Diffusion + Generation (Production) - Dissipation. They can thus be written as

Turbulent Kinetic Energy $(k)$ equation:

$$
\begin{aligned}
& \frac{\partial(\bar{u} k)}{\partial x}+\frac{\partial(\bar{v} k)}{\partial y}=\frac{\partial}{\partial x}\left\{\frac{1}{\rho}\left(\mu_{l}+\frac{\mu_{t}}{\sigma_{k}}\right) \frac{\partial k}{\partial x}\right\} \\
& +\frac{\partial}{\partial y}\left\{\frac{1}{\rho}\left(\mu_{l}+\frac{\mu_{t}}{\sigma_{k}}\right) \frac{\partial k}{\partial y}\right\}+G-\rho \varepsilon
\end{aligned}
$$

Where, the term $G$ corresponds to the turbulent shear production rate (due to energy transfer from the mean flow to turbulence by the mean velocity gradient) of the turbulent kinetic energy, $k$ while $\rho \varepsilon$ is its destruction rate. $\mathrm{G}$ can be expressed in terms of velocity gradients and turbulent viscosity as:

$$
G=\mu_{t}\left[2\left\{\left(\frac{\partial \bar{u}}{\partial \bar{x}}\right)^{2}+\left(\frac{\partial \bar{v}}{\partial y}\right)^{2}\right\}+\left(\frac{\partial \bar{u}}{\partial y}+\frac{\partial \bar{v}}{\partial x}\right)^{2}\right]
$$

Turbulent dissipation rate $(\varepsilon)$ equation:

$$
\begin{aligned}
& \frac{\partial(\bar{u} \varepsilon)}{\partial x}+\frac{\partial(\bar{v} \varepsilon)}{\partial y}=\frac{\partial}{\partial x}\left\{\frac{1}{\rho}\left(\mu_{l}+\frac{\mu_{t}}{\sigma_{\varepsilon}}\right) \frac{\partial \varepsilon}{\partial x}\right\} \\
& +\frac{\partial}{\partial y}\left\{\frac{1}{\rho}\left(\mu_{l}+\frac{\mu_{t}}{\sigma_{\varepsilon}}\right) \frac{\partial \varepsilon}{\partial y}\right\}+C_{1} \frac{\varepsilon}{k} G-C_{2} \rho \frac{\varepsilon^{2}}{k}
\end{aligned}
$$

Here, $\mathrm{C} \mu, \mathrm{C}_{1}, \mathrm{C}_{2}, \sigma_{k}$ and $\sigma_{\varepsilon}$ are the empirical turbulence constants, the values of which have been accepted from (Launder and Spalding, 1974) are given in table1.

Table1. Values of empirical turbulence constants

$$
\begin{array}{llllll}
\begin{array}{c}
\text { Standard } k-\varepsilon \\
\text { turbulence } \\
\text { model }
\end{array} & \mathrm{C}_{\mu} & \mathrm{C}_{1} & \mathrm{C}_{2} & \sigma_{\mathrm{k}} & \sigma_{\varepsilon} \\
& & & & & \\
\hline
\end{array}
$$

All the mathematical models formulated with sets of partial differential equations are subjected to some appropriate boundary conditions. The choice of CFD code of FLUENT for the study is based on the fact that the more common control volume based technique adopted in commercial FLUENT version 6.3 software package is used to convert differential form of the governing equations to algebraic form of the equations. The control volume method (CVM) is more efficient and easier to program in terms of CFD code development for computing the solution of incompressible turbulent flows The CVM method enjoys an advantage in memory use and speed for very large complicated problems like turbulent flows and source term dominated flows (premixed combustion) etc. The most popular turbulent model like standard $k-\varepsilon$ model available directly in FLUENT software code is well described in the literature and has been used in this situation for 
analyzing complicated turbulent flow fields in an elbow. The computational effort in terms of CPU time per iteration is much less for standard $k-\varepsilon$ model than any other turbulence models employed for solving the complicated turbulent flow fields.

The turbulence model, standard $k-\varepsilon$ is derived by assuming that the flow is fully turbulent and the effects of molecular viscosity are negligible. For locations near walls, the standard $k-\varepsilon$ model, therefore, demands an additional model, which comprises the effects of molecular viscosity. The standard $k-\varepsilon$ model is therefore valid only for fully turbulent flows and no-slip condition at wall is taken into consideration. The model constants as taken in computation may have default value. The comparisons show that the standard $k-\varepsilon$ model does not indicate the best agreement with experimental data for the same flow conditions in an elbow. The $k-\varepsilon$ model can not predict the results precisely.

The inputs files that were used for FLUENT version 6.3 software are also used for the current study. The test input parameters are generated to match the simulation process in the software. The computational 2-D domain and grid, along with assumed boundary conditions related to the present test case are also generated for incompressible turbulent flow field in an elbow. The transportation of turbulence flow in an elbow is then simulated using a standard $k-\varepsilon$ turbulence model with standard wall functions. The length of the computational domain is to be chosen such that the local Reynolds number at the exit section of the elbow must be assumed high, which is needed for the fully developed turbulent flow at the exit of the elbow. A second-order upwind scheme is used for spatial discretization for the momentum and turbulence transport equations. The air properties and other input values used in the simulation process were to take from the FLUENT database. Symmetry boundary conditions are also assumed in the upper and lower wall, as resolving the near-wall flow field is not as important as resolving the compressible Newtonian turbulent air flow field for this numerical experimentation.

For validation of CFD code used in the present study, the computed turbulent mean axial velocity distributions were compared with experimental results [51] for the same geometrical configuration with turbulent air flow and imposing identical conditions for both cases. The predicted velocity distributions at different station locations were compared with the experimental values for a qualitative match and overall reliability. There should be a visual similarity between the computed and experimental results in terms of general trend and curvature (near bends) etc. The relative error of the computed result from the experimental data at any station-distance along $\mathrm{x}$-axis or $\mathrm{y}$-axis direction did not exceed 8.0 percent in respect of large range values of turbulent Reynolds number. Moreover, the streamline contours and velocity vector plots obtained using CFD FLUENT code are able to qualitatively and reliably predict the turbulent flow field of air along the elbow length considered for the current numerical study.

\section{Boundary conditions}

The boundary conditions (B.C.) considered for the present study can be formulated as follows:

Inlet: $\mathrm{u}=\overline{\mathrm{u}}_{\mathrm{in}}=5 \mathrm{~m} / \mathrm{s}$ and $\mathrm{v}=\overline{\mathrm{v}}_{\mathrm{in}}=0$. Accordingly, $\operatorname{Re}_{\text {in }}=\frac{\rho \bar{u}_{\text {in }} \mathrm{W}}{\mu_{\text {air }}}=4.09 \times 10^{4}$, this has been kept constant.

Turbulence intensity (I) of inflow at inlet $\mathrm{I}=10 \%$ of the incoming fluid flow turbulence intensity. Distribution of the turbulence flow parameters at inlet are described as $\mathrm{k}_{\mathrm{in}}=(0.5) \times \mathrm{I} \times\left(\mathrm{U}_{\mathrm{in}}^{2}\right)$ and $\varepsilon_{\text {in }}=\mathrm{C}_{\mu}^{3 / 4} \mathrm{k}_{\text {in }}^{\frac{3}{2}} /(\mathrm{Kw})$ where $\mathrm{K}=0.41, \mathrm{w}=0.135 \mathrm{~m}$.

\section{Wall: No-slip condition (Except injection slot)}

$$
\overline{\mathrm{u}}=\overline{\mathrm{v}}=0 ; \frac{\partial \mathrm{k}}{\partial \mathrm{y}}=\frac{\partial \boldsymbol{\varepsilon}}{\partial \mathrm{y}}=0
$$

Injection slot: $\overline{\mathrm{u}}=\overline{\mathrm{u}}_{\mathrm{inj}}=0 ; \quad \overline{\mathrm{v}}=-\overline{\mathrm{v}}_{\mathrm{inj}}$ and turbulence Intensity, $\mathrm{I}=\operatorname{Iinj}=10 \%$ for the given physical model. The dimensionless injection velocity (Reinj) through the injection slot can now be written as $\operatorname{Re}_{\text {inj }}=\frac{\rho \times \bar{v}_{\text {inj }} \times \mathrm{w}_{\text {inj }} \text { ) }}{\mu_{\text {air }}}$

\section{Axis:}

$$
\frac{\partial \bar{u}}{\partial y}=\frac{\partial \varepsilon}{\partial y}=\frac{\partial \mathrm{k}}{\partial \mathrm{y}}=\overline{\mathrm{v}}=0, \text { for the mainstream }
$$

flow through the elbow considering symmetric flow.

\section{Outlet:}

The pressure of fluid at outlet is $\mathrm{P}_{\text {outlet }}=\mathrm{P}_{\text {atmosphere }}$

\section{Wall Function:}

Standard wall function is considered as follows:

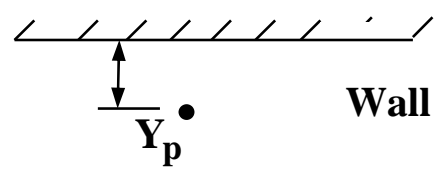


Near wall region $\mathrm{y}^{+}=\frac{\mathrm{y} \times \mathrm{u}_{\tau}}{v}$ and $\mathrm{u}_{\tau}=\sqrt{\frac{\tau_{\mathrm{w}}}{\rho}} \cdot \mathrm{u}_{\tau}$ is the friction velocity, and dimensionless velocity becomes $\mathrm{u}^{+}=\frac{\mathrm{u}}{\mathrm{u}_{\tau}}$, in viscous layer velocity profile becomes $\mathrm{u}^{+}=\mathrm{y}^{+}$

$\tau_{w}=\frac{\rho \bar{u}_{p} C_{\mu} \mu^{1 / 4 k^{1 / 2} \chi}}{\operatorname{In}\left(E \eta_{p}\right)}, \quad \eta_{p}=\frac{\rho k^{1 / 2} C_{\mu}{ }^{1 / 4 y} p}{\mu}$ where $y_{p}$ is the near wall point and $\eta_{p}>11.63$, $E=9.0$. This corresponds to the requirement that the kand $\varepsilon$ equations must be integrated up to the buffer region and not up to the wall and the equilibrium condition is generation $=$ dissipation i.e. $\mathrm{G}=\rho \varepsilon$ The corresponding $\mathrm{k}-\varepsilon$ at the near wall point is: $k_{p}=\frac{u_{\tau}{ }^{2}}{C_{\mu}{ }^{1 / 2}}$ and $\varepsilon_{p}=\frac{u_{\tau}{ }^{3}}{\chi} \eta_{p}, u_{\tau}$ is the friction velocity given by

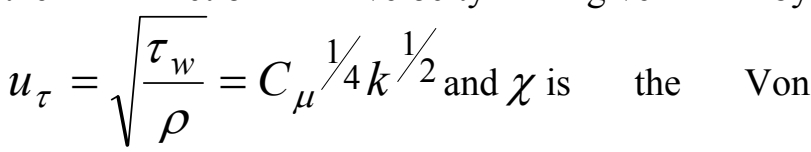
Karman constant having value 0.42 . This is the standard wall function which is used along with the modified $k-\varepsilon$ model.

Table 2. Turbulent flow velocity details for injection slot width $0.03 \mathrm{~m}$

\begin{tabular}{ccccc}
$\mathrm{W}_{\text {inj }}(\mathrm{m})$ & $\mathrm{u}_{\text {in }}(\mathrm{m} / \mathrm{s})$ & $\mathrm{V}_{\text {inj }}(\mathrm{m} / \mathrm{s})$ & $(\mathrm{VR})$ & $\left(\mathrm{Re}_{\text {inj }}\right)$ \\
\hline & & 2.0 & 0.4 & 3635 \\
& & & & \\
0.03 & 5.0 & 4.0 & 0.8 & 7271 \\
& & 6.0 & 1.2 & 10906 \\
\hline
\end{tabular}

Table 2 contains velocity details used for numerical calculation.

\section{Results and Discussion}

The turbulent flow patterns near the bends can be visualized from streamline contours as well as velocity vector plots shown in Figures 2 and 3 respectively. Three strong recirculation zones have been generated near the bend regions. In the lower part of the upper horizontal limb the possible existence of the largest re-circulation zone has been identified as Recirculation-3. The results show that the secondary flow creates the generation of a number of recirculation zone of different sizes and the possibilities of formation of vortices for turbulent flow fields in elbow. A considerable amount of kinetic energy of the developing mainstream flow is lost due to generation of recirculating flows. Figure 5 further shows the clear front views of three separate recirculation bubbles of different sizes generated in presence of the effect of three different radial injection flow velocities an injection slot of width $\mathrm{W}_{\mathrm{inj}}=0.03 \mathrm{~m}$. It is understandable that the recirculation- 2 as indicated in Figures 2, 3 and 5 becomes gradually smaller and weaker as the value of velocity ratio increases. The size (length and height) of each recirculation bubble has also been determined in the present numerical study.

The computation of incompressible twodimensional turbulent flow with imposed boundary conditions concerns determination of mean axial velocity profiles in a flow field at different station distances along the upper horizontal limb of the elbow geometry. Distributions of the mean stream wise velocity component $(\overline{\mathrm{u}})$ for the turbulent flow of the working fluid air $(\operatorname{Pr} \approx 0.71)$ at different station-distance ratios like $\mathrm{x} / \mathrm{L}=0.5510,0.5578$, $0.5850,0.6802,0.7482,0.8163,0.8843$ and 0.9863 in the downstream of the wall injector are plotted in Figures 4 for three different injection velocities $\left(\mathbf{R e}_{\text {inj }}\right)$ of air flow. It is now observed for first three station-distance ratios that all the distribution profiles of the mean velocity component $(\overline{\mathbf{u}})$ are with their respective peak values exist close to the centre line of the elbow.

Secondly, from Figures 4 the numerical result plots show the development of mean axial velocity profiles with possible existence of a recirculation zone due to the secondary flow as the value of station-distance ratio with respect to the total length increases along the bottom wall of the upper horizontal limb of the elbow. Further, the flow goes downstream, the maximum axial velocity moves toward the top wall and as a result, the velocity profiles are slightly distorted and a clear velocity peak develops near the top wall. The developing velocity profiles however show no influence of secondary flow resulting in reattachment of the mainstream flow in downstream end of the elbow. Near the duct outlet, the velocity peak weakens and the profiles become smoother indicating a likely to 
be fully developed turbulent flow at the exit of the elbow.

From the plots it is clear that the $k-\varepsilon$ model prediction is not very encouraging. Probably this attribution is due to the fact that a $k-\varepsilon$ model provides very poor results in recirculating flow and it requires quite modifications particularly to take care of the stream line curvatures as discussed detail in [52].
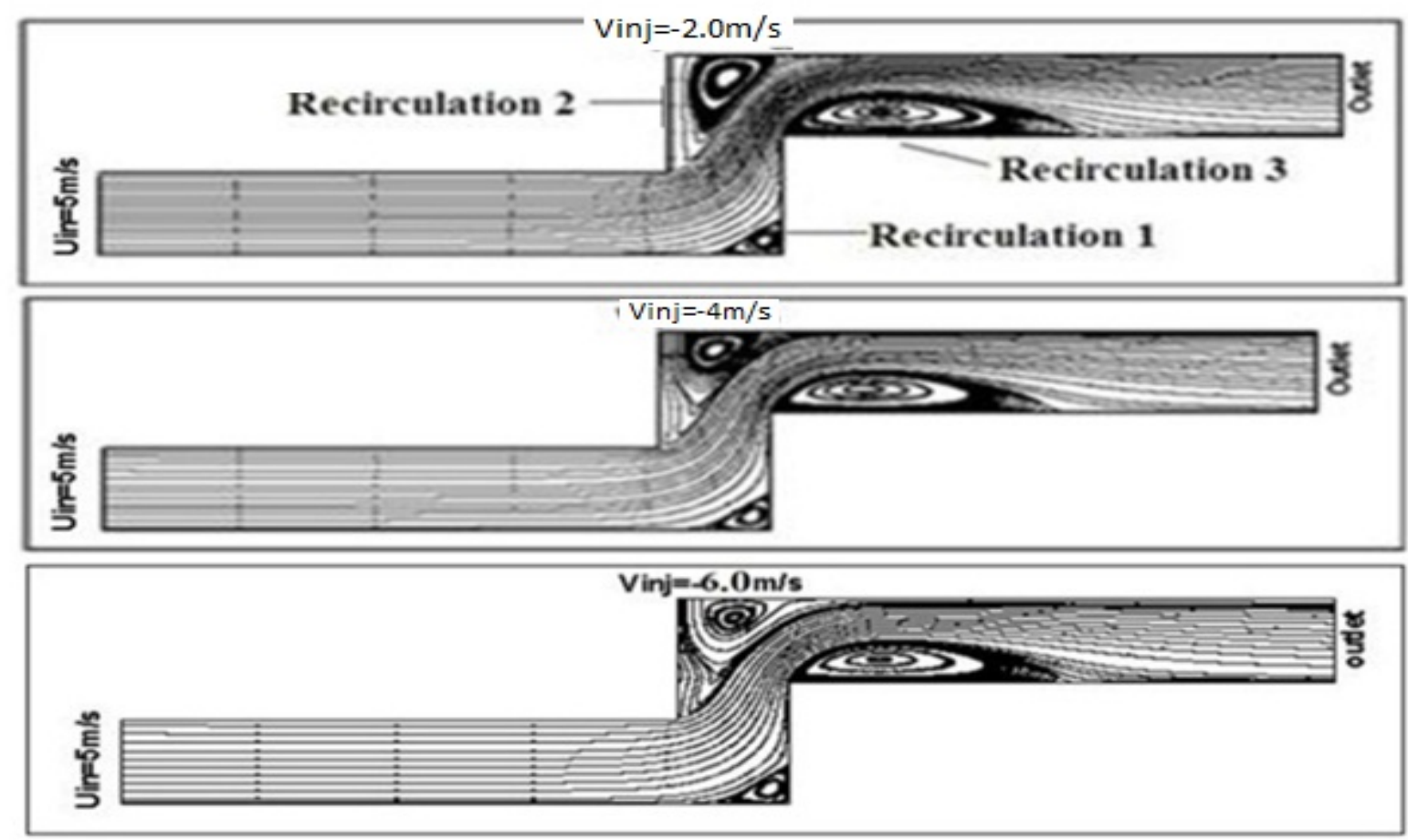

Figure 2. 2-D Streamline contour at different injection velocities.

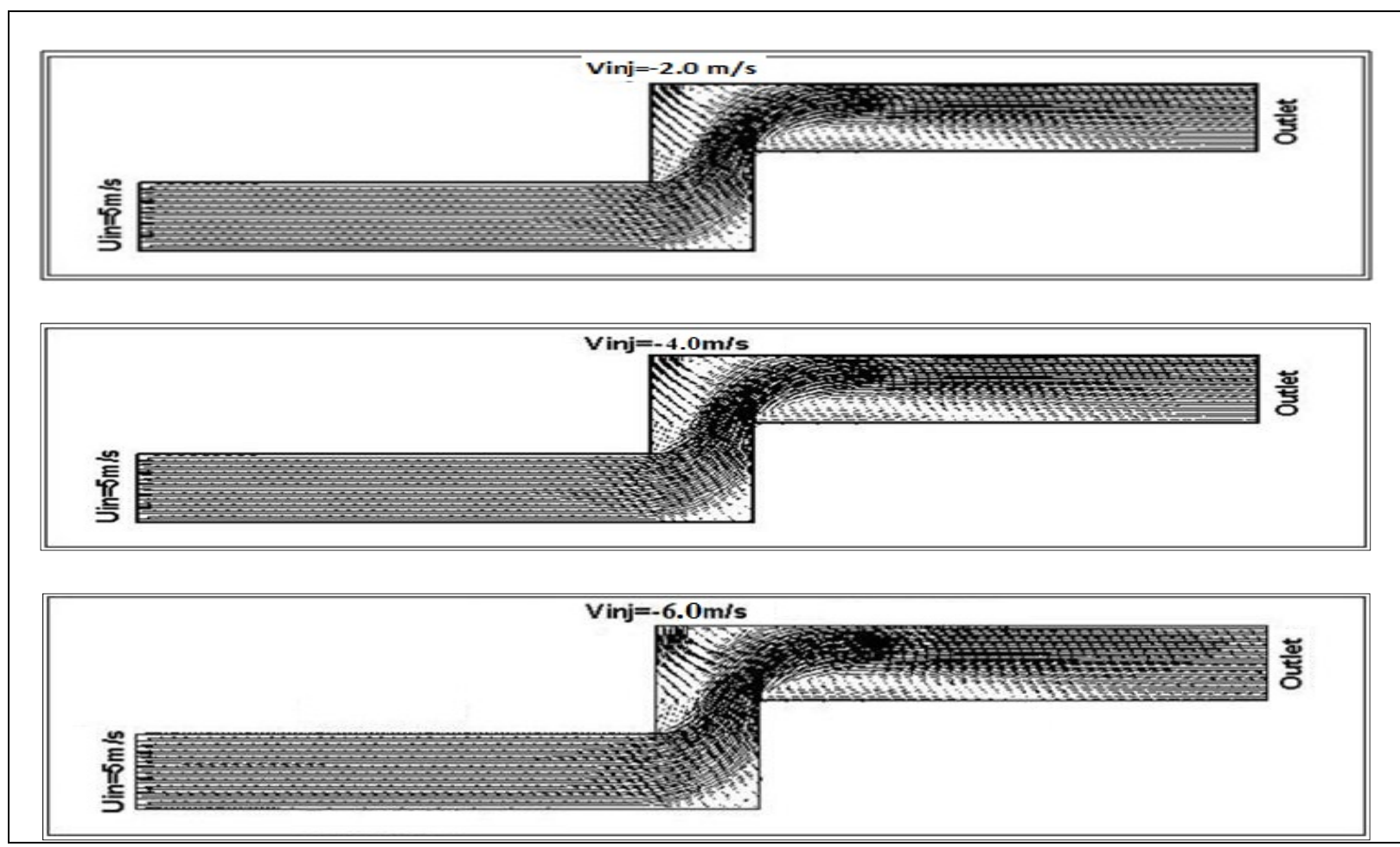

Figure 3. Velocity vector plots along the elbow length at different injection velocities. 
The secondary or the reverse flow is inducted by the transverse pressure gradient or due to negative pressure occurred in the mainstream turbulent flow indicating the existence of flow separation near the bend regions in an elbow. The other important parameter like local skin friction factor has been evaluated from the velocity field. The average values of friction factor $\left(\mathrm{C}_{\mathrm{f}}\right)$ at different axial station distances of the elongated length $S(m)$ downstream of the wall-injector have been plotted in Figure 6 for both the walls. The maximum local friction factor occurs in the third recirculation zone, then decreases and finally increases asymptotically along the bottom wall far downstream of the injection slot. For upper wall, the occurrence of maximum local friction factor is closer to the third recirculation zone, and then decreases. Finally the variation shows constant values far downstream of the injection slot. Friction experienced by the main stream turbulent flow along the upper wall is comparatively higher than that of the lower wall.

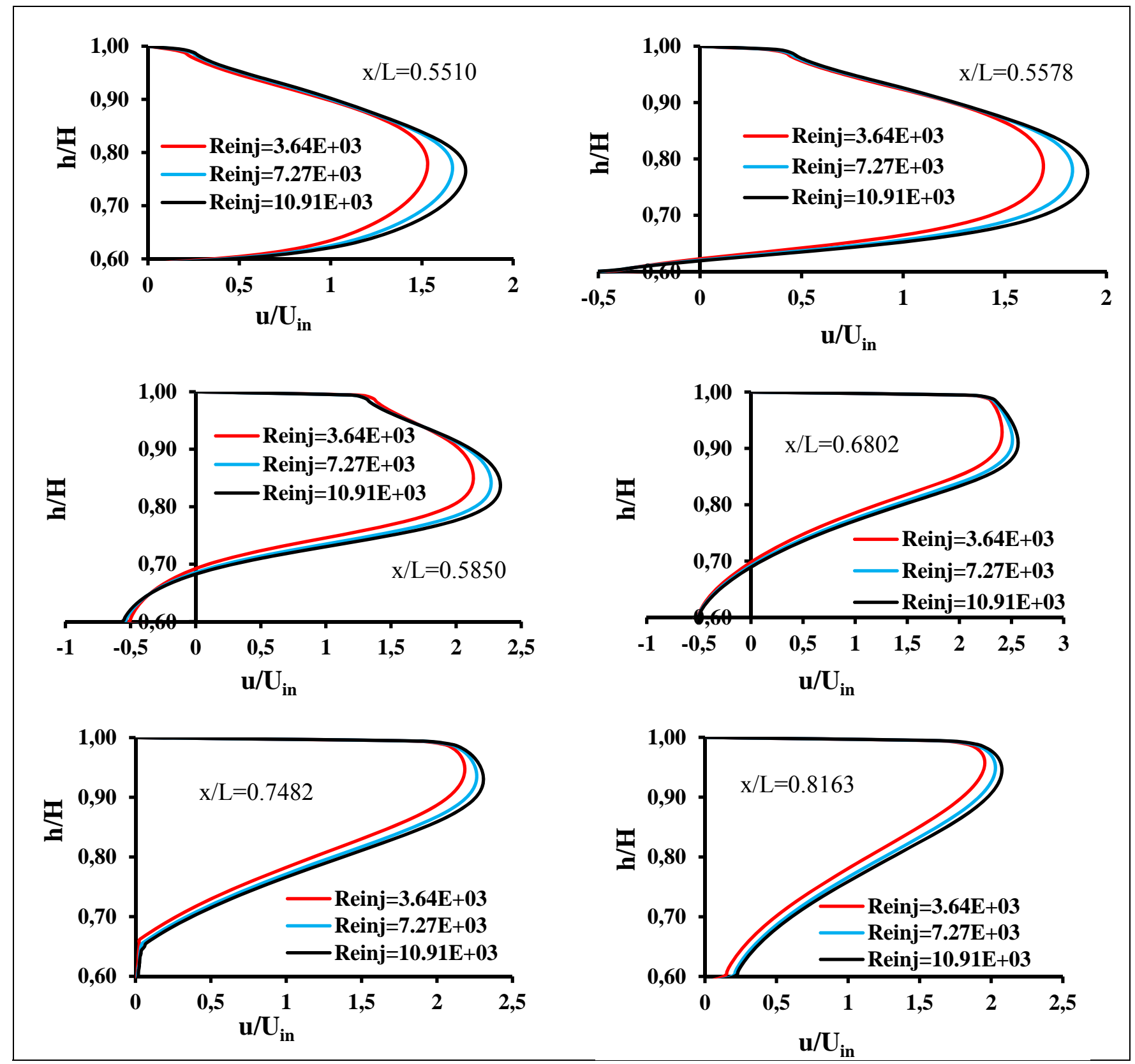



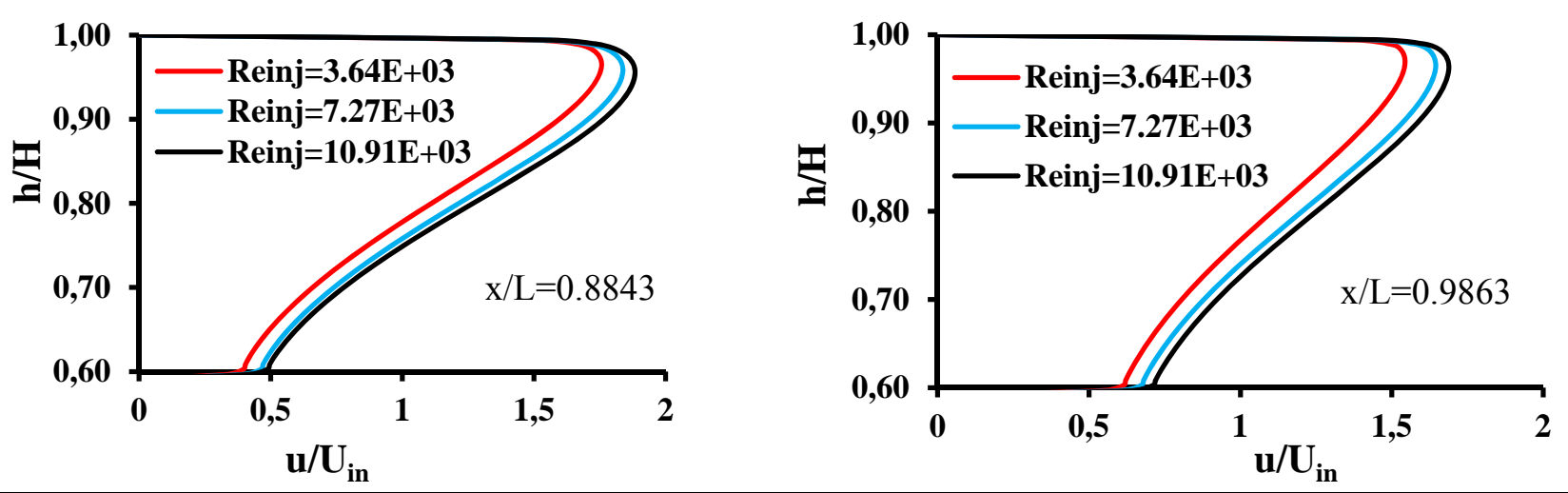

Figure 4. Distribution of mean velocity component $(\overline{\mathbf{u}})$ at different stations

Table 3. Effect of different injection velocities on the size of recirculation bubbles

\begin{tabular}{cccccccc}
\hline $\mathrm{W}_{\text {inj }}(\mathrm{m})$ & $-\bar{V}_{\text {in }}(\mathrm{m} / \mathrm{s})$ & \multicolumn{2}{c}{ Recirculation-1 } & Recirculation-2 & Recirculation-3 \\
\hline & & $\begin{array}{c}\text { Length } \\
(\mathrm{m})\end{array}$ & $\begin{array}{c}\text { Height } \\
(\mathrm{m})\end{array}$ & $\begin{array}{c}\text { Length } \\
(\mathrm{m})\end{array}$ & $\begin{array}{c}\text { Height } \\
(\mathrm{m})\end{array}$ & $\begin{array}{c}\text { Length } \\
(\mathrm{m})\end{array}$ & $\begin{array}{c}\text { Height } \\
(\mathrm{m})\end{array}$ \\
0.03 & 2.0 & 0.082 & 0.056 & 0.097 & 0.160 & 0.370 & 0.070 \\
& 4.0 & 0.085 & 0.054 & 0.095 & 0.073 & 0.360 & 0.066 \\
& 6.0 & 0.084 & 0.052 & 0.095 & 0.063 & 0.340 & 0.062 \\
\hline
\end{tabular}

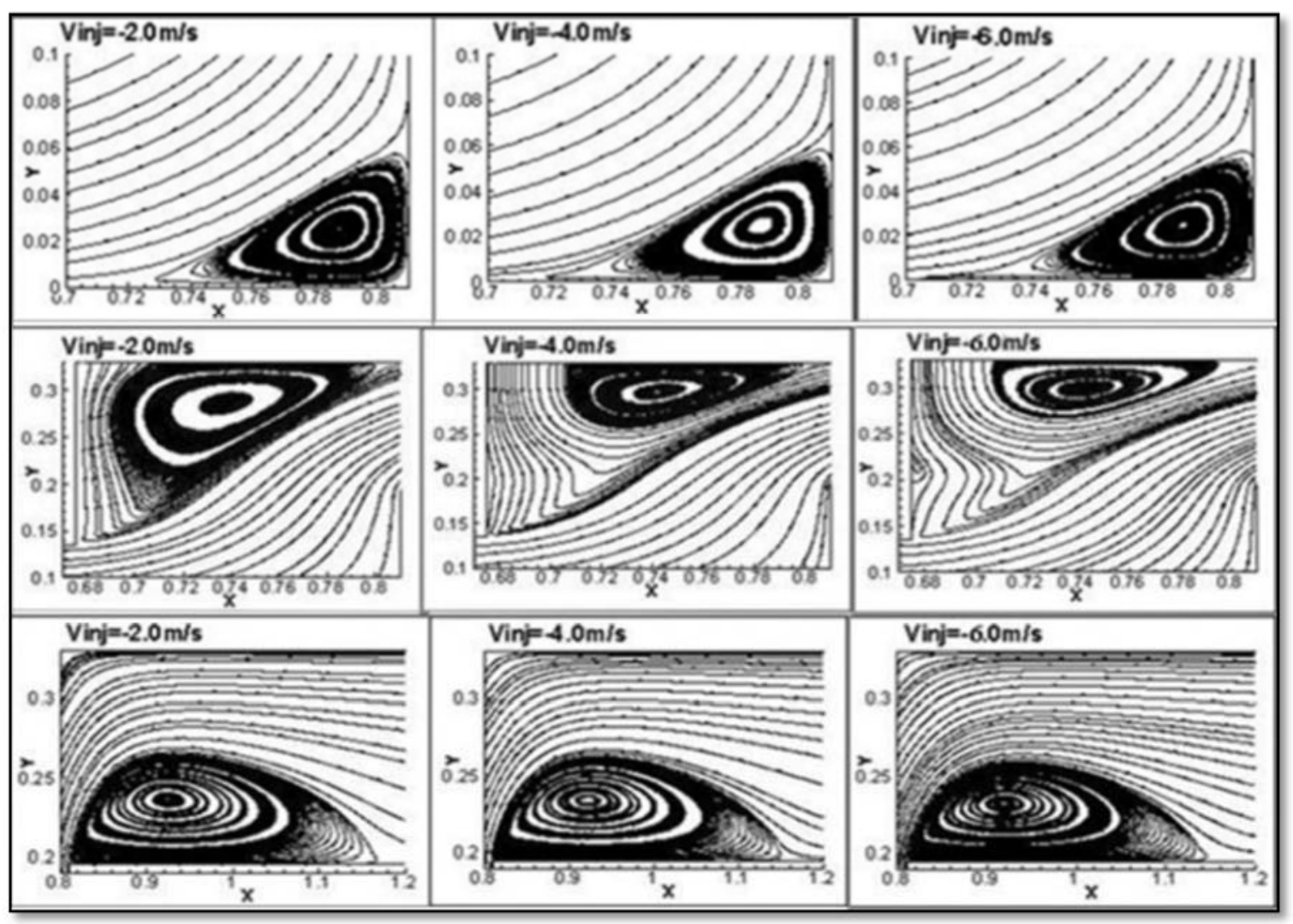

Figure 5. Front view of Recirculation bubbles generated in three separate zones 
Table 3 shows the final size of each of three recirculation bubbles in (X-Y) plane due to the effect of different injection velocities through an injection slot of width $\mathrm{w}_{\mathrm{inj}}=0.03 \mathrm{~m}$. The corresponding Figure 7 also shows the change of non-dimensional values of height to length ratio of the three recirculation bubbles in respect of increasing velocity ratios between the injection turbulent velocity and the velocity of the turbulent flow at inlet. A major effect of the increasing velocity ratio on the size and strength of the second recirculation bubble has been clearly observed for wall injector of width $\mathrm{w}_{\mathrm{inj}}=0.03 \mathrm{~m}$. It reveals that almost no effect on the third recirculation bubble and a minor effect on the first bubble are obvious from the Figure 7.

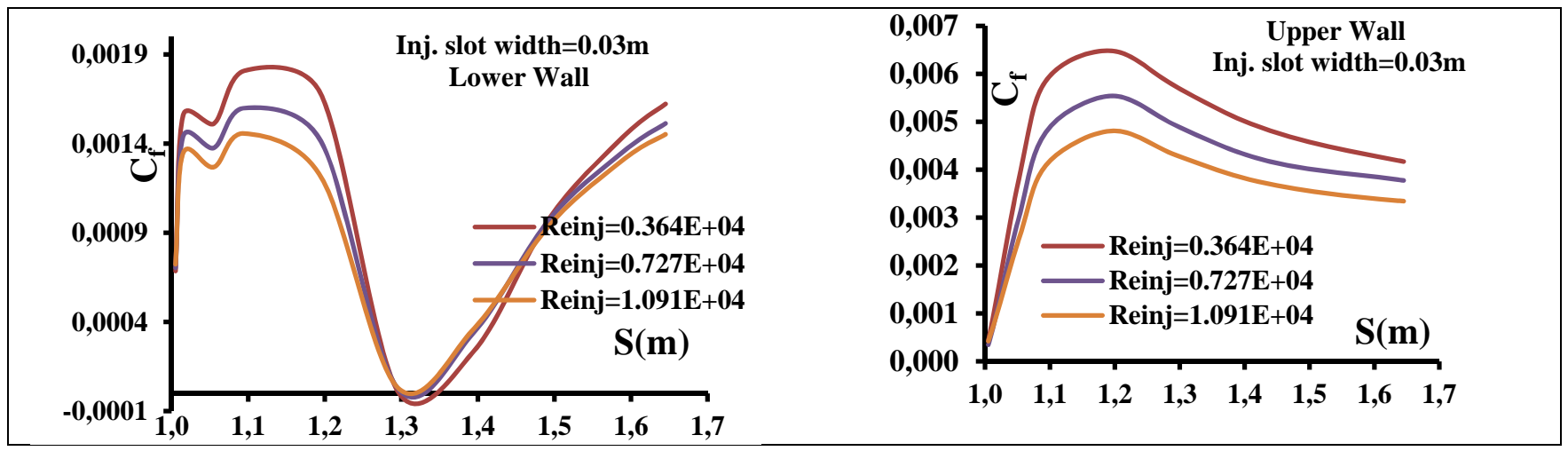

Figure 6. Distribution of local friction factor downstream wall injector

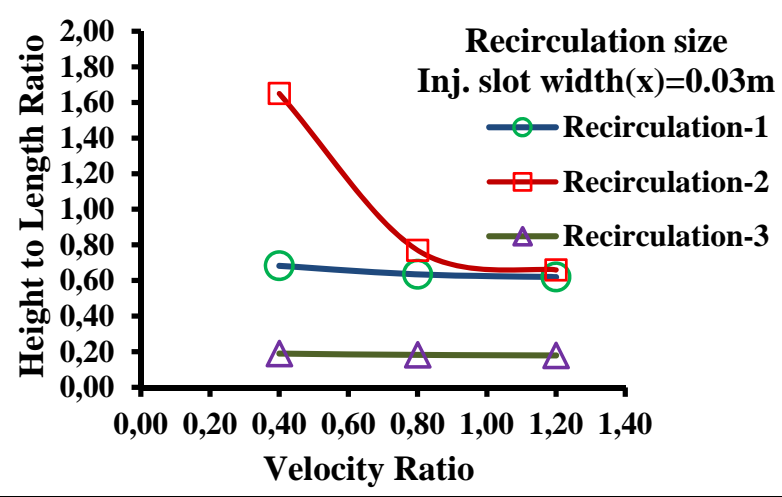

Figure 7. Effect of Velocity Ratio on size of Recirculation bubbles

\section{Conclusion}

In this paper, it was attempted to analyze and solve the complicated turbulent flow fields by using CFD code, FLUENT@ version 6.3 commercial software code. The computational results show clearly the complicated flow field including flow separation and reattachment behind the wall-injector. The variation of injection velocity has a profound effect on the velocity field and other parameters of the turbulent fluid. The local wall shear as well as friction factor along the upper wall of the elbow have been observed to decrease in the far downstream region of the top wall-injector with increase in injection velocity.

The current study ascertains that the size and strength of recirculation bubble reduces with increase of the side mass injection velocity or side mass Reynolds number. It also leads to a significant reduction of loss of the transport momentum energy of the turbulent fluid.

Finally, the current study also clears the facts that the performance of the forced convection turbulent flow in elbow ducts can practically be improved through the use of the technique - wall mass injection. The low cost, easy installation and maintenance associated with this technique are obviously more attractive compared to other techniques available. Moreover, the numerical study in the paper may encourage for experimental research work and design of energy saving-cum- 
efficient industrial heat exchanger, ducting system and equipment for engineering applications.

\section{Scopes for future research work}

The future research work is still required to assess the effects of many important aspects for dense single or double phase convection flows in ducts. Some useful directions which can lead to the way of future research work in the field of high potential fluid flow and heat transfer mechanisms for different bend ducts are as follows.

1. A detailed study of compressible fluid flow under unsteady and various boundary conditions will certainly be very useful in many engineering applications.

2. A research study for understanding the physical mechanism of the flow fields and heat transfer characteristics for the nonNewtonian fluids in different ducts and pipes etc. can be carried out in future.

3. A thorough investigation in 3-dimensional coordinates for pressure and velocity fields of turbulent fluid flow and heat transfer characteristics in bend ducts or pipes and other different complex geometries, under so many real conditions, will enormously explore the physics of the duct or pipe flows.

4. A future study considering the effects of (a) swirl motion of the turbulent fluid flow at inlet, (b) wall injection jet flows and (c) wall roughness on the both of steady and unsteady mixed turbulent convection flow field in three dimensional bend flows under variable property and conditions is essentially required in order to provide more realistic description of the transport phenomena in practice.

Moreover, the current study will help a lot to set up the feasible experimental work for research and design of energy saving-cum-efficient industrial heat exchanger, ducting system or equipment.

\section{NOMENCLATURE}

\begin{tabular}{|c|c|c|c|}
\hline$\overline{\mathbf{u}}, \overline{\mathbf{v}}$ & $\begin{array}{l}\text { Mean Velocity along } \mathrm{X} \text { and } \mathrm{Y} \text { axes } \\
\text { respectively, } \mathrm{m} / \mathrm{s}\end{array}$ & $\mu$ & $\begin{array}{l}\text { Co-efficient Dynamic viscosity of fluid } \\
\text { at room temperature, } \mathrm{kg} / \mathrm{ms}\end{array}$ \\
\hline$x$ & $\begin{array}{l}\text { The distance of the station } \\
\text { measured from the inlet end of the } \\
\text { elbow, } m\end{array}$ & $\begin{array}{l}\text { Re } \\
\text { L }\end{array}$ & $\begin{array}{l}\text { Reynolds number } \\
\text { Length of the duct }\end{array}$ \\
\hline$\rho_{\text {air }}$ & Density of air, $\mathrm{kg} / \mathrm{m}^{3}$ & $V_{\text {inj }}$ & Injection flow velocity, $\mathrm{m} / \mathrm{s}$ \\
\hline$k, \varepsilon$ & $\begin{array}{l}\text { Turbulent Kinetic energy, } \mathrm{m}^{2} / \mathrm{s}^{2} \text { and } \\
\text { its dissipation rate, } \mathrm{m}^{2} / \mathrm{s}^{3}\end{array}$ & $d u / d y$ & $\begin{array}{l}\text { Velocity gradient of the upper and } \\
\text { lower wall of the elbow }\end{array}$ \\
\hline$T$ & Absolute temperature, $\mathrm{K}$ & $\mathbf{R e}_{\text {inj }}$ & Reynolds number of injection flow \\
\hline$w_{i n j}$ & Injection slot width, $\mathrm{m}$ & G & Turbulent shear production rate \\
\hline $\mathbf{I}$ & Turbulence Intensity, \% & $\mathbf{C}_{\mathbf{f}}$ & Local skin friction factor \\
\hline$-\bar{V}_{i n j}$ & Injection Velocity, $\mathrm{m} / \mathrm{s}$ & S & Total Elongated Length, m \\
\hline 2-D & Two Dimensional & $k, \omega$ & $\begin{array}{l}\text { Turbulent Kinetic energy, } \mathrm{m}^{2} / \mathrm{s}^{2} \text { and its } \\
\text { specific dissipation rate, } 1 / \mathrm{s}\end{array}$ \\
\hline
\end{tabular}




\section{References}

[1] Dutta, P. and Nandi, N., Effect of Reynolds Number and Curvature Ratio on Single Phase Turbulent Flow in Pipe Bends, Mechanics and Mechanical Engineering, Lode University of Technology, Vol. 19 (1), 2015, pp.5-16.

[2] Wang, S., Ren, C., Sun, Y., Yang, X., Tu, J., A Study on the Instantaneous Turbulent Flow Field in a 90-Degree Elbow Pipe with Circular Section, Science and Technology of Nuclear Installations, Vol. 2016, 2016, pp.1-8.

[3] Wu, X., Lin, L., Luo, X., Chen, J., Dai, J., Study on Flow Field Characteristics of the $90^{\circ}$ Rectangular Elbow in the Exhaust Hood of a Uniform Push-Pull Ventilation Device, International Journal of Environmental Research and Public Health, Vol.15 (2884), 2018, pp.1-12.

[4] Debnath, R., Bhattacharjee, S., Roy, D. and Majumder, S., Experimental Analysis of the Turbulent fluid flow through a Two Dimensional Rectangular Elbow, Proceedings of the 53rd Congress of the ISTAM (An International Meet), Civil Engg. Dept., Osmania Univ., Secunderabad, India, 2008, pp.184-190.

[5] MOSSAD, R., YANG, W., SCHWARZ, M.P., NUMERICAL PREDICTION OF AIR FLOW IN A SHARP $90^{\circ}$ ELBOW, Seventh International Conference on CFD in the Minerals and Process Industries, CSIRO, Melbourne, Australia, 9-11 December 2009, pp.1-5.

[6] Hossain, Md. S., Hossain, Md. I., Computational Investigation of Turbulent Flow Development in $180^{\circ}$ Channel with Circular Cross Section, EJERS European Journal of Engineering Research and Science, Vol.3(12), December 2018, pp.98-105.

[7] Hossain, Md. S., Hossain, Md. I., Pramanik, S., Ahmed, J.U., Analyzing the Turbulent Flow Characteristics by Utilizing k- $\varepsilon$ Turbulence Model, EJERS European Journal of Engineering Research and Science, Vol. 2(11), November 2017, pp.28-34.

[8] Rathore, M., Mondloe, D.S., Upadhyay, S., C., Computational Investigation of Fluid Flow $90^{\circ}$ bend Pipe Using Finite Volume Approach, International Research Journal of Engineering and Technology,Vol.4(6), June 2017, pp.18281833.

[9] Baydar, E. and Ozmen, Y., An experimental and numerical investigation on a confined impinging air jet at high Reynolds numbers, Applied Thermal Engineering, Vol.25, 2005, pp. 409-421.

[10] Devahastin, S. and Mujumdar, A. S., A Numerical Study of Flow and Mixing Characteristics of Laminar Confined Impinging Streams, Chem. Engg. Journal, Vol. 85, 2002, pp. 215-223.

[11] Kalita, K., Dewan, A., and Dass, A. K., Prediction of Turbulent Plane Jet in Cross flow, Numerical Heat Transfer, Part A, Vol. 41, 2002, pp. 101-111.

[12] Ramaprian, B. R. and Haniu, H., Turbulence Measurements in Plane Jets and Plumes in Cross flow. Technical Report No. 266, IIHR, University of Iowa, Iowa City, North America. 1983.

[13] Haniu, H. and Ramaprian, B. R., Studies on Two-Dimensional Curved Non-buoyant Jets in Cross flow, ASME Journal of Fluids Engineering, Vol. 111, 1989, pp. 78- 86.

[14] Devahastin, S., Mujumdar, A. S., A Study of Turbulent Mixing of Confined Impinging Streams Using a New Composite Turbulence Model,Ind. Eng. Chem. Res., Vol. 40 (22), 2001, pp. 4998-5004.

[15] Hold, A. E., Calay, R. K. and O'Brien, M., Flows generated by the interaction of an inlet and a cross-flow, J. Wind Engg. and Industrial Aerodynamics, Vol. 88, 2000, pp. 1-23.

[16] Ricou, F. P., and Spalding, D. B., Measurements of Entrainment by AxiSymmetrical Turbulent Jets, J. Fluid Mech., Vol. 11, 1961,pp. 21-32.

[17] Olson, R. M. and Eckert, E. R. G., Experimental studies of turbulent flow in a porous circular tube with uniform fluid injection through the tube wall, ASME J. Appl. Mech., Vol. 33, 1966, pp. 7-17.

[18] Exley, J. T. and Brighton, J. A., Flow Separation and Reattachment in Confined Jet Mixing, ASME J. Basic Eng., Vol. 93, 1971, pp. 192-198.

[19] Elghobashi, S. E., Pun, W. M., and Spalding, D. B., Concentration Fluctuations in Isothermal Turbulent Confined Coaxial Jets, Chem. Eng. Sci., Vol. 32, 1977, pp. 161-166.

[20] Andreopoulos, J. and Rodi, W., Experimental Investigation of Jets in a Cross flow. J. Fluid Mech., Vol.138, pp. 93-127.

[21] Pietrzyk, J. R., Bogard, D. G. and Crawford, M. E., Hydrodynamic Measurements of Jets in a Cross-flow for Gas Tubine Film Cooling Applications, Journal of Turbomachinery, Vol. 111, 1988, pp. 139-145. 
[22] Khodadadi, J. M. and Vlachost, N. S., Experimental and Numerical Study of Confined Coaxial Turbulent Jets, AIAA Journal, Vol. 27(5), 1989, pp. 532-541.

[23] Yang, J., Tsai, B., and Tsai, G., SeparatedReattaching Flow over a Back step with Uniform Normal Mass Bleed, ASME J. Fluids Eng., Vol. 116, 1994, pp. 29-35.

[24] Roy, J. C., Bertrand, C., Numerical and Experimental Study of Mixed and Forced Convection in a Junction, Int. J. Heat Mass Transfer, Vol. 37, 1994, pp.1985-2006.

[25] Chang, Y. R. and Chen, K. S., Prediction of opposing turbulent line jet discharged laterally into a confined cross-flow, Int. J. Heat Mass Transfer, Vol. 38(9), 1995. pp. 1693-1703.

[26] Fric, T. F., Roshko, A.,Vortical structures in the wake of a transverse jet, J. Fluid Mech., Vol. 279, 1994, pp. 1-47.

[27] Kelso, R.M., Lim, T. T., Perry, A. E., An experimental study of round jet in cross-flows, J. Fluid Mech. Vol. 306, 1996, pp. 111-144.

[28] Dianat, M., Fairweather, M. and Jones, W. P., Predictions of axi-symmetric and twodimensional impinging turbulent jets, Int. J. Heat Fluid Flow, Vol. 17,1996, pp. 530-538.

[29] Launder, B.E. and Spalding, D. B., The Numerical Computation of Turbulent Flows, Computer Methods in Applied Mechanics and Engineering, Vol. 3(2), 1974, pp. 269-289.

[30] Patankar, S. V., Basu, D. K. and Alpay, S. A., Prediction of Three-Dimensional Velocity Field of a Deflected Turbulent Jet, ASME Journal of Fluid Engineering, Vol. 99, 1977, pp. 758-762.

[31] Catalano, G. D., Chang, K. S. and Mathis, J. A., Investigation of Turbulent Jets Impingement in a Confined Cross flow, AIAA Journal, Vol.27, 1989, pp. 1530-1535.

[32] Hwang, R. R. and Chiang, T. P., Numerical Simulation of Vertical Forced Plume in a Cross flow of Stably Stratified Fluid, ASME Journal of Fluids Engineering, Vol. 117, 1995, pp. 696705.

[33] He, G., Guo, Y. and Hsu, A. T., The Effect of Schmidt Number on Turbulent Scalar Mixing in a Jet-in-Cross flow, Int. Journal of Heat Mass Transfer, Vol. 42, 1999, pp. 3727-3738.

[34] Ajersch, P., Zhou, J. M., Ketler, S., Salcidean, M., and Gartshore, I. S. Multiple Jets in a Cross Flow: Detailed Measurements and Numerical Simulations. ASME J. Fluids Eng., Vol.119, 1997, pp. 330-342.
[35] Liou, T.-M., Liao, C.-C., Chen, S.-H. and Lin, H.-M., Study on Side-Jet Injection near a duct entry with various Injection angles, J. Fluid Engg. (ASME), Vol. 121, 1999, pp. 580-587.

[36] Ali, M., Fujiwara, T. and Leblanc, J. E., Influence of main flow inlet configuration on mixing and flame holding in transverse injection into supersonic airstream. Int. J. Eng. Sci., Vol.38, 2000, pp. 1161-11180.

[37] Hahn, S., Je, J., and Choi, H., Direct Numerical Simulation of Turbulent Channel Flow with Permeable Walls. J. Fluid Mech., Vol. 450, 2002, pp. 259-285.

[38] Nirmolo, A., Optimization of Radial Jets Mixing in Cross-flow of Combustion chambers using Computational Fluid Dynamics. Dissertation submitted for the degree of Dr.Ing. at Otto-von-Guericke-University of Magdeberg, Germany, 2007, pp. 1-120.

[39] Beheshti, B. H., Ghorbanian, K., Farhanieh, B., Teixeira, J. A. and Ivey, P. C., A new design for tip injection in transonic axial compressor. Proceedings ASME Turbo Expo.: 2006, Barcelona, Spain, GT2006-90007, May 8-11, 2006.

[40] Cassina, G., Beheshti, B. H., Kammerer, A. and Abhari, R. S., Parametric study of tip injection in axial flow compressor stage. Proceedings ASME Turbo Expo.: 2007, Montreal, Canada, GT2007-27403, May 14-17.

[41] Disimile, P. J., and Toy, N., The Vortex Dominated Flow Field Associated with a Confined Jet in a Cross Flow, Int. J. Dyn. Fluids, Vol. 2(2), 2006, pp.155-169.

[42] Ko, T. HA, Numerical Study on the Effects of Side Inlet Angle on the Mixing Phenomena in a Three Dimensional Side Sump Combustor, Int. Commun. Heat Mass Transfer, Vol. 33, 2006, pp.853-862.

[43] Pathak, M., Dewan, A. and Dass, A.K., Effect of streamline curvature on flow field of a turbulent plane jet in cross-flow, Mechanics Research Communications, Vol. 34, 2007, pp. 241-248.

[44] Majumder, S. and Sanyal, D., Relaminerization of Axi-Symmetric Turbulent Flow with Combined Axial Jet and Side Injection in a Pipe, ASME J. Fluids Eng., Vol. 132, 2010, pp. 101101/1-6.

[45] Saha, D., Majumder, S., Sanyal, D., Numerical analysis of the main turbulent flow through an axi-symmetric circular duct with the side mass injection at various injection angles, Int. J. Eng. Sci. Tech., Vol. 2(6), 2010, pp. 1561-1568. 
[46] Kumar, A. and Das, M. K., Study of a turbulent dual jet consisting of a wall jet and an offset jet, ASME J. Fluids Engg., Vol. 133, 2011, pp. 101102/1-11.

[47] Majumder, S., Saha, D. and Das, P., Numerical simulation of twin turbulent side mass injection into a cross flow through a circular duct. Int. J. Eng. Sci. Res., Vol. 3(5), 2012, pp. 825-833.

[48] Dae-Woong Kim, Jin-Hyuk Kim and KwangYong Kim, Aerodynamic Performance of an Axial Compressor with a Casing Groove Combined with Injection, Transactions of the Canadian Society for Mechanical Engineering, Vol. 37(3), 2013, pp. 283-292.

[49] Ma, K. and Lai, H., Comparison of Five TwoEquation Turbulence Models for Calculation of Flow in $90^{\circ}$ Curved Rectangular Ducts, J. App. Fluid Mechanics, Vol. 9(6), 2016, pp. 29172931.

[50] Patankar, S.V., Numerical Heat Transfer and Fluid Flow, Hemisphere Publishing Corp., New York, 1980.
[51] Mandal, A., Bhattacharjee, S., Debnath, R., Roy, D., Majumder, S., Experimental Investigation of Turbulent Fluid Flow through a Rectangular Elbow, International Journal of Engineering Science and Technology, Vol. 2(6), 2010, pp.1500-1506.

[52] Debnath, R., Bhattacharjee, S., Mandal, A., Roy, D. and Majumder, S., A COMPERATIVE STUDY WITH FLOW VISUALIZATION OF TURBULENT FLUID FLOW IN AN ELBOW, Int. Journal Engg. Sc. and Tech., Vol. 2(9), 2010, pp. 4108-4121.

Creative Commons Attribution License 4.0 (Attribution 4.0 International , CC BY 4.0)

This article is published under the terms of the Creative Commons Attribution License 4.0

https://creativecommons.org/licenses/by/4.0/d eed.en_US 